\title{
Editorial do dossiê "Confisco, medidas cautelares patrimoniais, pretensão civil cumulada e garantias processuais penais" - Novos mecanismos de restrições patrimoniais e a proteção de direitos fundamentais
}

\author{
Editorial of dossier "Confiscation, cumulated civil claim \\ and criminal procedure guarantees" - New instruments \\ to constrain assets and the protection of fundamental rights
}

José Javier Estrada Contreras ${ }^{1}$

Universidad Modelo, Mérida, Yucatán, México javier@modelo.edu.mx orcid.org/0000-0003-0859-1418

Vinicius Gomes de Vasconcellos ${ }^{2}$

Universidade Estadual de Goiás, Goiânia, Goiás, Brasil Instituto Brasiliense de Direito Público, Brasília, Distrito Federal, Brasil vinicius.vasconcellos@ueg.br lattes.cnpq.br/9628659956663949 Dorcid.org/0000-0003-2020-5516 p publons.com/a/1174099/

1 Doctor en Derecho mención "Cum Laude" por la Universitat Jaume I, de Castellón de la Plana, España; Licenciado en Derecho por la Universidad Autónoma de Yucatán. Director del Centro de Investigaciones Silvio Zavala y Profesor en la Escuela de Derecho de la Universidad Modelo, en Mérida, Yucatán.

2 Doutor em Direito pela Universidade de São Paulo, com período de sanduíche na Universidad Complutense de Madrid/ESP (bolsa PDSE/CAPES) e estágio de pós-doutoramento pela Universidade Federal do Rio de Janeiro. Mestre em Ciências Criminais pela PUCRS. Professor permanente do Instituto Brasiliense de Direito Público - IDP/DF (mestrado/doutorado). Professor efetivo da Universidade Estadual de Goiás. Editor-chefe da RBDPP. Assessor de Ministro no Supremo Tribunal Federal. 
Resumo: Este editorial pretende expor pontos pertinentes relacionados à temática de confisco e medidas patrimoniais para restrição de bens potencialmente oriundos de atividades ilícitas. Isso pode ocorrer no próprio âmbito processual penal ou em ações de natureza civil, como a extinção de domínio mexicana. De qualquer modo, existem inúmeros questionamentos sobre a legitimidade de tais medidas, como em termos de proteção de direitos fundamentais, o que perpassa a apresentação dos artigos publicados neste dossiê.

Palavras-chave: editorial; medidas patrimoniais; perda de bens; confisco; pretensão civil cumulada; garantias processuais penais.

ABSTRACT: This editorial aims to analyze relevant topics related to confiscation and patrimonial restrictions to constrain assets that potentially have illicit origin. That may be implemented in the criminal process itself or in civil claims, like the Mexican "extinción de dominio". In both perspectives, there are many possible issues about legitimacy of those mechanisms, like in terms of protection of individual guarantees and rights, that are examined in the articles published in this dossier.

KEY-WORDS: editorial; patrimonial restrictions; assets constrain; confiscation; cumulated civil claim; criminal procedure guarantees.

Em um momento em que a persecução penal volta-se à face financeira (follow the money) das organizações criminosas e dos delitos em rede (como discurso de ódio e temas correlatos a fake news), o dossiê agora publicado na Revista Brasileira de Direito Processual Penal almejou primordialmente analisar os instrumentos - chamados de modo distinto em cada país - por meio dos quais o Estado, para combater o crime organizado, busca bens de origem ou destino potencialmente ilícitos, por meio de um processo judicial e com o objetivo de declarar a perda do direito de propriedade sobre esses ativos. Isso geralmente ocorre em pretensões derivadas ou vinculadas a um processo criminal, cujo conhecimento e resolução podem ser atribuídos ao próprio juiz do caso criminal ou, dependendo da situação, a diferentes juízes, inclusive civis.

Em países como o México, por exemplo, existem basicamente duas possibilidades. A primeira é o desenvolvimento de um "processo 
civil cumulado", perante o juiz competente no caso criminal, com objeto na pretensão de natureza patrimonial para reparação contra o acusado-réu ou contra aqueles que possuem apenas o status de uma parte passiva civil. A segunda é o processo de extinção da propriedade, que acarreta a perda dos direitos que uma pessoa possui em relação aos bens sujeitos a esse procedimento, sem contraprestação ou qualquer compensação ao seu proprietário ou àqueles que possuem ou se comportam como tal, nem para quem, sob quaisquer circunstâncias, possui ou mantém esses bens. A extinção da propriedade é declarada por sentença de uma autoridade judicial distinta da competente no caso penal, por meio de um processo autônomo e independente daquele de onde deriva e cujos fatos possuem aparente tipicidade que fundamenta a pretensão de extinção do domínio. ${ }^{3}$

Sobre a sistemática da extinção de domínio mexicana, Jorge Rivero Evia descreve que a ação civil de extinção de domínio possui quatro requisitos: 1) a existência de um fato ilícito; 2) a existência de bens produto do ilícito ou que foram utilizados para o seu cometimento; 3 ) o nexo causal entre os dois primeiros requisitos; e, 4) que o proprietário do bem tenha conhecimento de tais atividades ilícitas. Contudo, a comprovação do "fato ilícito" na seara do procedimento de natureza civil pode ocorrer de modo independente ao processo penal, sem a necessidade, por exemplo, de verificação da culpabilidade do agente. Considerando tal cenário, o autor examina as categorias fundamentais da extinção de domínio a partir de construções de direito penal material e da teoria do delito. ${ }^{4}$

3 Sobre isso, na doutrina brasileira: ROCHA, Silvio L. F.; MORGANTI, Daniela M. A constitucionalidade do confisco alargado e da ação de extinção de domínio. Revista Magister de Direito Penal e Processual Penal, v. 16, n. 93, p. 26-35, dez./jan. 2020; VASCONCELOS, André P. Extinção civil do domínio. Perdimento de bens. Belo Horizonte: Del Rey, 2011. Sobre projeto de lei para introduzir espécie de ação civil pública para extinção de domínio no Brasil: RIOS, Rodrigo Sánchez; PUJOL, Luiz Gustavo. Confisco alargado: reflexões acerca de suas possibilidades no ordenamento jurídico brasileiro. Revista Brasileira de Ciências Criminais, São Paulo, v. 24, n. 118, p. 123-158, jan./fev. 2016.

4 RIVERO EVIA, Jorge. La acción civil de extinción de dominio: el retorno al cuerpo del delito. Revista Brasileira de Direito Processual Penal, Porto Alegre, vol. 6, n. 2, mai./ago. 2020 
Em uma perspectiva mais ampla, Francisco José Parra Lara expõe a tendência de expansão dos instrumentos de apropriação de bens pelo Estado, cada vez mais percebidos com finalidades punitivas, o que ocorre por meio de ação de natureza civil assim denominada. O autor questiona a constitucionalidade e a convencionalidade da atuação estatal que toma o domínio de patrimônios cuja procedência legítima não possa ser comprovada. Assim, conclui que tal processo de natureza civil deve ser suprimido em prol da realização das restrições patrimoniais em um procedimento penal com todas as garantias a ele inerentes. ${ }^{5}$

Como exposto no edital de chamada de autores ao dossiê, pretendia-se promover o debate científico em torno desses instrumentos, em relação aos diferentes contextos - nacionais e internacionais - e a partir das recentes mudanças normativas e das múltiplas decisões dos tribunais nacionais e supranacionais. Foram destacados os temas da natureza jurídica de ambos os procedimentos (quando existirem) e seu vínculo com as garantias do processo criminal a que derivam; sobre os efeitos que podem ter sobre a coisa julgada nos processos criminais de origem, e inclusive entre esses dois processos derivados; sobre as garantias processuais próprias, de acordo com sua natureza processual e, especialmente, se houver o risco de fragilização das garantias processuais do réu.

Esse debate mostra-se atual e extremamente relevante ao cenário brasileiro, onde também se discute a perda de bens como efeito da condenação ou como pena autônoma. ${ }^{6}$ Recentemente inserido no ordenamento pela Lei 13.964/19 (denominada Lei Anticrime), o confisco alargado foi previsto no art. 91-A do Código Penal nos seguintes termos: "Na hipótese de condenação por infrações às quais a lei comine

5 PARRA LARA, Francisco José. Extinción de Dominio en México: Revisión de su estructura constitucional y convencional Revista Brasileira de Direito Processual Penal, Porto Alegre, vol. 6, n. 2, mai./ago. 2020.

6 Sobre isso e a natureza da medida, remete-se a: ESSADO, Tiago E. Perda de bens e o novo paradigma para o processo penal brasileiro. Rio de Janeiro: Lumen Juris, 2015. p. 6-17; CORRÊA JÚNIOR, Alceu. Confisco penal: alternativa à prisão e aplicação aos delitos econômicos. São Paulo: IBCCRIM, 2006. p. 3942; LINHARES, Solon C. Confisco de bens. Uma medida penal, com efeitos civis contra a corrupção sistêmica. São Paulo: RT, 2016. p. 165-174; SILVESTRE, Raquel C. R. Perda de bens. Efeito da sentença condenatória. Salvador: JusPodivm, 2018. p. 23-36. 
pena máxima superior a 6 (seis) anos de reclusão, poderá ser decretada a perda, como produto ou proveito do crime, dos bens correspondentes à diferença entre o valor do patrimônio do condenado e aquele que seja compatível com o seu rendimento lícito".

Sem dúvidas, trata-se de dispositivo inovador no ordenamento brasileiro, que demandará ampla discussão doutrinária e jurisprudencial. Um ponto que imediatamente se destaca é a possível crítica relacionada à inversão do ônus da prova, ${ }^{7}$ pois a referida perda se dá sem a necessidade de efetiva comprovação pela acusação da origem ilícita dos bens, o que, na redação acima transcrita, parece ser presumido da "diferença entre o valor do patrimônio do condenado e aquele que seja compatível com o seu rendimento lícito". O que depois é ressaltado pelo $\S 2^{\circ}$ do mesmo artigo: "O condenado poderá demonstrar a inexistência da incompatibilidade ou a procedência lícita do patrimônio".

Essa questão é analisada por Luiz Eduardo Dias Cardoso, tanto em relação ao novo dispositivo quanto a mecanismo semelhante previsto na

7 Sobre isso, remete-se a: BARGI, Alfredo. 'Processo al patrimonio' e principi del giusto processo: regola probatorie e regole decisorie nella confisca penale. In: BARGI, Alfredo; CISTERNA, Alberto (coord.). La giustizia patrimoniale penale. Torino: UTET, 2011, p. 3-48; CAEIRO, Pedro. Sentido e função do instituto da perda de vantagens relacionadas com o crime no confronto com outros meios de prevenção da criminalidade reditícia (em especial, os procedimentos de confisco e a criminalização do enriquecimento "ilícito"). Revista Brasileira de Ciências Criminais, a. 21, n. 100, p. 453-501, jan./fev. 2013. Ainda, em relação aos possíveis conflitos entre normas nacionais e supranacionais, ver: GAITO, Alfredo; FURFARO, Sandro. Giustizia penale patrimoniale. Archivio penale, n. 3, p. 1-18, 2016. Na doutrina brasileira: BERTONCINI, Mateus E.; GUARAGNI, Fábio A.; MACEDO, Gustavo H. Modelos de constatação de provas em lides de improbidade administrativa e confisco alargado no processo penal. Revista Relações Internacionais no Mundo Atual, v. 3, n. 24, p. 1-19, 2019.

Nesse debate, há quem sustente que a presunção de inocência pode ser restringida ao se tratar de questões patrimoniais posteriores ao juízo da culpabilidade penal do imputado: ESSADO, Tiago E. Perda de bens e o novo paradigma para o processo penal brasileiro. Rio de Janeiro: Lumen Juris, 2015. p. 268-271. De modo semelhante: LINHARES, Solon C. Confisco de bens. Uma medida penal, com efeitos civis contra a corrupção sistêmica. São Paulo: RT, 2016. 189-190; LOPES, João Felipe Menezes. Confisco de bens como instrumento de combate à criminalidade organizada: análise dos regimes estrangeiros e de sua compatibilidade com o ordenamento jurídico brasileiro. Revista da AJU$F E$, v. 28 , n. 95 , p. $207-240,2^{\circ}$ sem. 2015. 
Lei 11.343/06 (art. 63-F, inserido pela Lei 13.886/19), afirmando que há inversão do ônus probatório na previsão inserida no art. 91-A do CP, mas não naquela do art. 63-F da Lei de Drogas. Fundamenta tal afirmação na constatação de que no texto do CP foi excluído parágrafo que assentava "a decretação da perda prevista no caput fica condicionada à existência de elementos probatórios que indiquem conduta criminosa habitual, reiterada ou profissional do condenado ou sua vinculação à organização criminosa”, o qual consta na Lei de Drogas e seria determinante para a consolidação de um ônus probatório ao acusador. ${ }^{8}$

Previamente à inserção da perda alargada, os mecanismos tradicionais de restrição patrimonial eram objeto de críticas por sua inefetividade e de propostas de alterações para aprimoramentos. Sem dúvidas, além das novas discussões sobre a recente alteração, subsistem fundamentais questionamentos em relação ao sistema já antes previsto no CPP brasileiro. ${ }^{9}$

Em relação à medida assecuratória patrimonial de sequestro, Guilherme Lucchesi e Ivan Zonta analisam questões relevantes sobre os limites à solidariedade na restrição patrimonial nos casos de crimes cometidos em coautoria. Assim, sustentam que, diferentemente da obrigação de reparar o dano (que possui natureza solidária por expressa previsão do Código Civil), o perdimento deve observar estritos limites subjetivos, em respeito à intranscendência da pena, e, consequentemente,

8 CARDOSO, Luiz Eduardo Dias. A inversão do ônus da prova na decretação da perda alargada: entre o Código Penal e a Lei n. 11.343/06. Revista Brasileira de Direito Processual Penal, Porto Alegre, vol. 6, n. 2, maio/ago. 2020. Do mesmo autor, já anteriormente afirmando a constitucionalidade da perda alargada a partir do exemplo da Diretiva 2014/42 da União Europeia: SOUZA, Cláudio M.; CARDOSO, Luiz Eduardo D. A perda alargada em face da principiologia processual penal brasileira. Revista Brasileira de Ciências Criminais, São Paulo, v. 24, n. 118, p. 233-271, jan./fev. 2016.

9 Nesse sentido, cita-se relevante pesquisa realizada no Projeto do governo federal denominado Pensando o Direito: AMARAL, Thiago Bottino do (Coord.). Medidas assecuratórias do processo penal. Série Pensando o Direito (n. 25/2010). No que diz respeito ao regime previsto no CPP: GIMENES, Marta Cristina Cury Saad. As medidas assecuratórias do Código de Processo Penal como forma de tutela cautelar destinada à reparação do dano causado pelo delito. 2007. Tese (Doutorado em Direito Processual Penal) - Faculdade de Direito, Universidade de São Paulo, São Paulo. 
isso também deve ser atendido na hipótese de sequestro, como medida assecuratória que visa a constringir bens que, ao final, serão atingidos pelo perdimento. ${ }^{10}$

Em termos de direito comparado, ${ }^{11}$ além dos exemplos mexicano e brasileiro, o dossiê conta com artigos relacionados aos regimes alemão, espanhol, português e estadunidense. A partir do exemplo do ordenamento de Portugal, Gabriel Marson Junqueira analisa importantes questões sobre cooperação jurídica internacional quando embasada em confisco non-conviction based. $\mathrm{O}$ autor conclui que "o modelo de reconhecimento mútuo, nos dias de hoje, abrange quer a perda clássica, quer a perda alargada, mas não qualquer das formas de confisco non-conviction based - civil ou em processo criminal". ${ }^{12}$

Já Javier Escobar Veas expõe a discussão existente nos Estados Unidos sobre a perda de bens em processos de natureza civil, sem as garantias comuns ao processo penal, o que gera tensões com a proibição de dupla persecução (double jeopardy clause). A partir do estudo de casos da Suprema Corte estadunidense, o autor afirma que os precedentes assentam inexistir violação ao double jeopardy clause quando o Estado apresenta paralelamente ação civil para perda de bens e processo penal, embora certos limites devam ser aplicados, como a vedação de multas excessivas. ${ }^{13}$

Em relação ao sistema alemão, Ana E. Carrillo del Teso examina nova legislação que realizou reforma para a recuperação de ativos penais

10 LUCCHESI, Guilherme Brenner; ZONTA, Ivan Navarro. Sequestro dos proventos do crime: limites à solidariedade na decretação de medidas assecuratórias. Revista Brasileira de Direito Processual Penal, Porto Alegre, vol. 6, n. 2, maio/ago. 2020

11 Sobre isso, ver também: VIEIRA, Roberto D. Confisco alargado de bens. Análise de direito comparado. Salvador: JusPodivm, 2019.

12 JUNQUEIRA, Gabriel Marson. A recuperação de ativos, o regime do reconhecimento mútuo e os pedidos de cooperação judiciária relacionados a confisco non-conviction based em Portugal. Revista Brasileira de Direito Processual Penal, Porto Alegre, vol. 6, n. 2, mai./ago. 2020.

13 ESCOBAR VEAS, Javier. The Constitutionality of Parallel Civil Forfeiture Proceedings and Criminal Prosecutions under the Double Jeopardy Clause in the United States. Revista Brasileira de Direito Processual Penal, Porto Alegre, vol. 6, n. 2, mai./ago. 2020. 
(Gesetz zur Reform der strafrechtlichen Vermögensabschöpfung), em vigor desde 1 de julho de 2017. Em tal alteração houve a atualização do regime de perda de bens tanto em termos materiais quanto processuais. A partir de tal cenário, a autora destaca pontos positivos e negativos das modificações, como na tensão sobre a natureza penal ou civil do mecanismo e a facilitação à reparação das vítimas. ${ }^{14}$

Por fim, no que diz respeito ao cenário espanhol, Nicolás Rodríguez-García e Omar Gabriel Orsi ressaltam a necessidade de uma proteção reforçada a terceiros afetados pela perda de bens de origem ilícita, especialmente com a sua participação no processo para exercício do contraditório. ${ }^{15}$ Trata-se de temática ainda mais pertinente ao debate brasileiro, pois o regime inserido no Código Penal pela Lei 13.964/19 definiu que a perda de bens deve recair sobre o patrimônio do condenado, que engloba bens "I - de sua titularidade, ou em relação aos quais ele tenha o domínio e o benefício direto ou indireto, na data da infração penal ou recebidos posteriormente; e II - transferidos a terceiros a título gratuito ou mediante contraprestação irrisória, a partir do início da atividade criminal" (art. 91-A, § $1^{\circ}$, CP).

\section{REFERÊNCIAS}

AMARAL, Thiago Bottino do (Coord.). Medidas assecuratórias do processo penal. Série Pensando o Direito (n. 25/2010). Disponível em: <http://pensando. mj.gov.br/wp-content/uploads/2015/07/25Pensando_Direito3.pdf >. Acesso em 11 jun. 2020.

BARGI, Alfredo. 'Processo al patrimonio' e principi del giusto processo: regola probatorie e regole decisorie nella confisca penale. In: BARGI, Alfredo; CISTERNA, Alberto (coord.). La giustizia patrimoniale penale. Torino: UTET, 2011, p. 3-48.

${ }^{14}$ CARRILLO DEL TESO, Ana E. Recuperación de activos en el sistema penal alemán: luces y sombras del actual régimen de decomiso de ganancias. Revista Brasileira de Direito Processual Penal, Porto Alegre, vol. 6, n. 2, maio/jun. 2020.

15 RODRÍGUEZ-GARCÍA, Nicolás; ORSI, Omar Gabriel. La protección reforzada en España de los terceros afectados por el decomiso de bienes ilícitos. Revista Brasileira de Direito Processual Penal, Porto Alegre, vol. 6, n. 2, mai./ ago. 2020. Também do primeiro autor: RODRÍGUEZ GARCÍA, Nicolás. El decomiso de activos ilícitos. Navarra: Aranzadi, 2017. 
BERTONCINI, Mateus E.; GUARAGNI, Fábio A.; MACEDO, Gustavo H. Modelos de constatação de provas em lides de improbidade administrativa e confisco alargado no processo penal. Revista Relações Internacionais no Mundo Atual, v. 3, n. 24, p. 1-19, 2019. https://doi.org/10.21902/revrima.v3i27.3927

CAEIRO, Pedro. Sentido e função do instituto da perda de vantagens relacionadas com o crime no confronto com outros meios de prevenção da criminalidade reditícia (em especial, os procedimentos de confisco e a criminalização do enriquecimento "ilícito"). Revista Brasileira de Ciências Criminais, a. 21, n. 100, p. 453-501, jan./fev. 2013.

CARDOSO, Luiz Eduardo Dias. A inversão do ônus da prova na decretação da perda alargada: entre o Código Penal e a Lei n. 11.343/06. Revista Brasileira de Direito Processual Penal, Porto Alegre, vol. 6, n. 2, maio/ago. 2020. https://doi. org/10.22197/rbdpp.v6i2.362

CORRÊA JÚNIOR, Alceu. Confisco penal: alternativa à prisão e aplicação aos delitos econômicos. São Paulo: IBCCRIM, 2006.

CARRILLO DEL TESO, Ana E. Recuperación de activos en el sistema penal alemán: luces y sombras del actual régimen de decomiso de ganancias. Revista Brasileira de Direito Processual Penal, Porto Alegre, vol. 6, n. 2, maio/jun. 2020. https://doi. org/10.22197/rbdpp.v6i2.355

ESCOBAR VEAS, Javier. The Constitutionality of Parallel Civil Forfeiture Proceedings and Criminal Prosecutions under the Double Jeopardy Clause in the United States. Revista Brasileira de Direito Processual Penal, Porto Alegre, vol. 6, n. 2, mai./ago. 2020. https://doi.org/10.22197/rbdpp.v6i2.338

ESSADO, Tiago E. Perda de bens e o novo paradigma para o processo penal brasileiro. Rio de Janeiro: Lumen Juris, 2015.

GAITO, Alfredo; FURFARO, Sandro. Giustizia penale patrimoniale. Archivio penale, n. 3, p. 1-18, 2016.

GIMENES, Marta Cristina Cury Saad. As medidas assecuratórias do Código de Processo Penal como forma de tutela cautelar destinada à reparação do dano causado pelo delito. 2007. Tese (Doutorado em Direito Processual Penal) - Faculdade de Direito, Universidade de São Paulo, São Paulo.

JUNQUEIRA, Gabriel Marson. A recuperação de ativos, o regime do reconhecimento mútuo e os pedidos de cooperação judiciária relacionados a confisco nonconviction based em Portugal. Revista Brasileira de Direito Processual Penal, Porto Alegre, vol. 6, n. 2, mai./ago. 2020. https://doi.org/10.22197/rbdpp.v6i2.294 
LINHARES, Solon C. Confisco de bens. Uma medida penal, com efeitos civis contra a corrupção sistêmica. São Paulo: RT, 2016.

LOPES, João Felipe Menezes. Confisco de bens como instrumento de combate à criminalidade organizada: análise dos regimes estrangeiros e de sua compatibilidade com o ordenamento jurídico brasileiro. Revista da AJUFE, v. 28, n. 95, p. 207-240, $2^{\circ}$ sem. 2015.

LUCCHESI, Guilherme Brenner; ZONTA, Ivan Navarro. Sequestro dos proventos do crime: limites à solidariedade na decretação de medidas assecuratórias. Revista Brasileira de Direito Processual Penal, Porto Alegre, vol. 6, n. 2, maio/ago. 2020. https://doi.org/10.22197/rbdpp.v6i2.353

PARRA LARA, Francisco José. Extinción de Dominio en México: Revisión de su estructura constitucional y convencional. Revista Brasileira de Direito Processual Penal, Porto Alegre, vol. 6, n. 2, mai./ago. 2020. https://doi.org/10.22197/rbdpp. v6i2.351

RIOS, Rodrigo Sánchez; PUJOL, Luiz Gustavo. Confisco alargado: reflexões acerca de suas possibilidades no ordenamento jurídico brasileiro. Revista Brasileira de Ciências Criminais, São Paulo, v. 24, n. 118, p. 123-158, jan./fev. 2016.

RIVERO EVIA, Jorge. La acción civil de extinción de dominio: el retorno al cuerpo del delito. Revista Brasileira de Direito Processual Penal, Porto Alegre, vol. 6, n. 2, mai./ago. 2020. https://doi.org/10.22197/rbdpp.v6i2.357

ROCHA, Silvio L. F.; MORGANTI, Daniela M. A constitucionalidade do confisco alargado e da ação de extinção de domínio. Revista Magister de Direito Penal e Processual Penal, v. 16, n. 93, p. 26-35, dez./jan. 2020.

RODRÍGUEZ GARCÍA, Nicolás. El decomiso de activos ilícitos. Navarra: Aranzadi, 2017.

RODRÍGUEZ-GARCÍA, Nicolás; ORSI, Omar Gabriel. La protección reforzada en España de los terceros afectados por el decomiso de bienes ilícitos. Revista Brasileira de Direito Processual Penal, Porto Alegre, vol. 6, n. 2, mai./ago. 2020. https://doi.org/10.22197/rbdpp.v6i2.360

SILVESTRE, Raquel C. R. Perda de bens. Efeito da sentença condenatória. Salvador: JusPodivm, 2018.

SOUZA, Cláudio M.; CARDOSO, Luiz Eduardo D. A perda alargada em face da principiologia processual penal brasileira. Revista Brasileira de Ciências Criminais, São Paulo, v. 24, n. 118, p. 233-271, jan./fev. 2016. 
VASCONCELOS, André P. Extinção civil do domínio. Perdimento de bens. Belo Horizonte: Del Rey, 2011.

VIEIRA, Roberto D. Confisco alargado de bens. Análise de direito comparado. Salvador: JusPodivm, 2019.

\section{Informações adicionais e declarações do autor (integridade científica)}

Declaração de conflito de interesses (conflict of interest declaration): os autores confirmam que não há conflitos de interesse na realização das pesquisas expostas e na redação deste editorial.

Declaração de autoria (declaration of authorship): todas e somente as pessoas que atendem aos requisitos de autoria deste editorial estão listadas como autores.

Declaração de ineditismo e originalidade (declaration of originality): os autores asseguram que o texto aqui publicado não foi divulgado anteriormente em outro meio e que futura republicação somente se realizará com a indicação expressa da referência desta publicação original; também atestam que não há plágio de terceiros ou autoplágio. 


\section{COMO CITAR ESTE EDITORIAL:}

ESTRADA CONTRERAS, José Javier; VASCONCELLOS, Vinicius G. Editorial do dossiê "Confisco, medidas cautelares patrimoniais, pretensão civil cumulada e garantias processuais penais" - Novos mecanismos de restrições patrimoniais e a proteção de direitos fundamentais. Revista Brasileira de Direito Processual Penal, Porto Alegre, vol. 6, n. 2, p. 527-538, mai./ago. 2020. https://doi.org/10.22197/rbdpp.v6i2.398

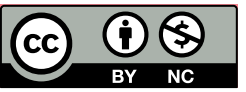

Esta obra está licenciada com uma Licença Creative Commons Atribuição-NãoComercial 4.0 Internacional. 